\title{
FLOOD EVACUATION ROUTES MAPPING BASED ON DERIVED- FLOOD IMPACT ANALYSIS FROM LANDSAT 8 IMAGERY USING NETWORK ANALYST METHOD
}

\author{
N. Watik ${ }^{1}$, L. M. Jaelani ${ }^{2}$ \\ ${ }^{1}$ Dept. of Geomatic Engineering, Institut Teknologi Sepuluh Nopember, Surabaya, Indonesia 60111 - nurwatik@its.ac.id \\ ${ }^{2}$ Dept. of Geomatic Engineering, Institut Teknologi Sepuluh Nopember, Surabaya, Indonesia 60111 - lmjaelani@ geodesy.its.ac.id
}

KEY WORDS: flood, network analyst, route analysis, flood simulation model, Landsat 8 imagery

\begin{abstract}
:
Reported by National Disaster Response Agency of Indonesia (BPBD) as many as 94 dies, 149 injured, and more than 88 thousands homeless caused by floods in 2018. Besides bringing casualties to people and environment, the floods also affect the damages to transportation infrastructures in which vital to disaster emergency response operation e.g. evacuation process. Due to the complex impact of current disaster, the demands of providing a short-term response increases accordingly. Therefore, this research proposes a prototype of flood evacuation route utilizing network analyst method. The network analyst method particularly focus on finding alternative route based on time and distance. This research uses a flood simulation model derived from Landsat 8 imagery and terrain data. Subsequently, the simulation model divides the flood severity based on the depth which consist of $<0.3 \mathrm{~m}$ (slight), $0.3-0.5 \mathrm{~m}$ (moderate), and $>0.5 \mathrm{~m}$ (serious) in order to generate an impact analysis regarding the estimation of damages and casualties. In order to resemble the real situation of flood, barriers (e.g. flood area) are applied into the finding evacuation route procedure. Thereby, the estimated evacuation route can be executed considering the safest and fastest way. Moreover, some comparisons between before and after flood are conducted in order to know the effectiveness of evacuation routes. By such comparison proves that network analyst enables to support disaster management operation with respect to handling the evacuation procedure.
\end{abstract}

\section{INTRODUCTION}

During the past decade, disasters are the major reason for many deaths, injuries, and homeless of populations along with extensive property damages remain. Supposedly, the casualties regarding to the mortality rate and sociality impact is caused by weather-related disasters, such as flood, tsunami, and landslide, particularly in the high period of moonsoons. As reported by National Disaster Response Agency of Indonesia (BPBD), floods caused as many as 94 dies, 149 injured, and more than 88 thousands homeless in 2018 (Zhacky, 2019). The flood impact not only happened to people and environment, but also transportation infrastructures damages in which vital to disaster emergency response operation (Huder, 2012) e.g. evacuation and resource deployment process.

A growing understanding about disaster impact inisiates the disaster-related organization demands particular actions in managing the disaster impact in order to enhance the resilience, preparedness, and response upon the disaster. In the most case, disaster management was associated with mapping to identify the impact particularly for doing response phase (ESRI, 2006; Esri, 2000; Mansourian et al., 2006). The mapping for disaster involves several technologies such as Global Positioning System (GPS), photogrammetry, remote sensing, and Geographic Information System (GIS). The use of which has been proven that spatial location is very crucial for identifying and indicating characteristic of the disaster and the scope of emergency response has grown tremendously over the past years (ESRI,2016; Tang et al, 2009).

Identifying water body is the important subject to extract flood simulation model. With a time series landsat data, water surface information can be extracted by several water surface interpretation technique. The extraction methods comprises object-based analysis (Dao, et al., 2015), water index algorithms detection (Mcfeeters, 2013), and classification methods (Westen, 2012) implementation. Such methods are essesial for determining flood occurence by distinguishing open water (permanent and temporary) and vegetation water from nonwater object.

As the most priority of disaster preparedness is saving lives and livelihoods (United Nations, 2008), disaster management should consider the response phase instead of identifying the characteristic of disaster only. Therefore, the procedure regarding response is implemented. Such of which is dealing with evacuation plan towards the casulaties by providing transportation networks (e.g. railroads, roads, traffic control points) (Gunes et al., 2001). The parameters of determining evacuation route composed of time, distance, and safety. Such parameters are familiar enabling in network analyst of ArcGIS, considering its capabilities in dealing with shortest and fastest route access (Nicoara \& Haidu, 2014),(Pasha, 2006). Network analyst is one of ArcGIS extensions for routing purpose based on network spatial analysis e.g. closest facility, point-to-point routing, drive-time analysis (Pasha, 2006).

Due to the complex impact of current disaster, this research purpose evacuation route based on flood simulation model derived from Landsat 8 and terrain data produced from DTM filter of Cosmo SkyMed Stripmap HIMAGE image. By using flood model simulation, the evacuation routes is executed based on the travel time and distance considering damage analysis due to the flood.

\section{STUDY AREA AND DATASET}

\subsection{Study Area}

The admistrative boundary of Surabaya is divided to 31 districts of 4 territorial boundaries composed of west, east, north, and 
south. Surabaya is located in $7^{\circ} 15^{\prime} 55^{\prime \prime} \mathrm{S}$ and $112^{\circ} 44^{\prime} 33^{\prime \prime} \mathrm{E}$. Based on Meteorology, Climate, Geophysic Agency (BMKG) monitoring, Indonesia has 2 seasons composed of rainy and dry. Due to the topographical location, Indonesia has various topography condition which triggers the diversity of climate change. Based on the analysis of last 30 years (1981-2010), climatologically Indonesia has 407 climate patterns, of which 342 patterns are seasonal zone (meaning that clearly differentiate between rainy and dry season) and non-zone (meaning that of which has 2 times maximum rainfall in a year or where throughout the year the rainfall is always high or low (BMKG, 2019). Surabaya is categorized into the seasonal zone whose high period of rainy season occured from October to March.
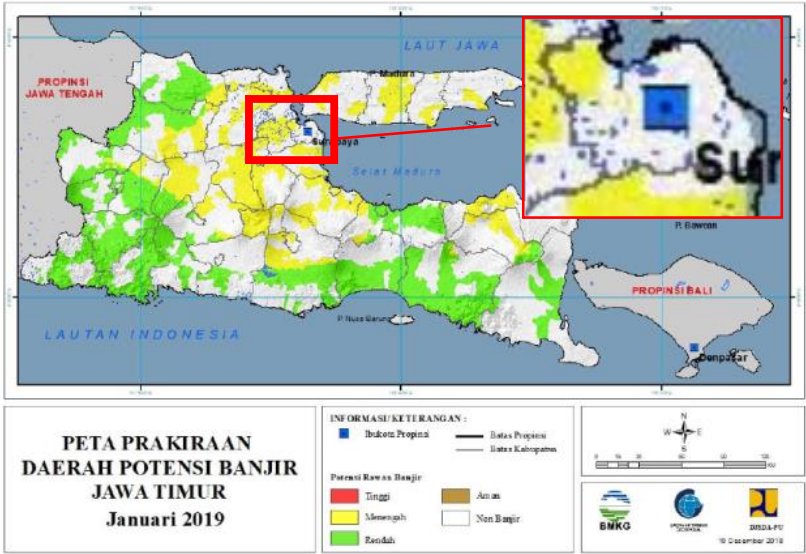

Figure 1. Flood Potential Map of East Java, Indonesia

Based on the geographical location of Surabaya whose coastal area around, flood periodically occurs in particular area. Figure 1 shows flood potential map of East Java for January 2019. The severity level is divided into high, medium, and slight, indicated by red, yellow, and green respectively. Sukomanunggal, Tandes, and Benowo are identified as the most vulnerable districts of flood potential in Surabaya. Therefore, this research chose West of Surabaya as the study area. The study area composed of Tandes, Sukomanunggal, Sambikerep, Lakarsantri, Benowo, Pakal, and Asemrowo district.

\subsection{Landsat 8}

Three different aqcuisition time of Landsat 8 image were collected to detect water surface for predicting inundation area of flood occured on March 13, 2014. These images were chosen considering water surface changes before and after flood event. Before conducting water surface detection approaches, the images were georeferenced to UTM zone 49S, corrected radiometrically and atmospherically using FLAASH (Fast Line of Asmospheric Analysis radiative transfer) to produce surface reflectance or Bottom of Atmospher (BoA). The catalogue of landsat dataset used in this research described in table 1.

Table 1. The catalogue of Landsat image used

\begin{tabular}{|l|c|}
\hline Acquisition Date & Cloud cover \% \\
\hline November 1, 2013 & 6.13 \\
March 25, 2014 & 6.38 \\
\hline
\end{tabular}

\subsection{Terrain data}

Terrain data was extracted from Digital Surface Model (DSM). The DSM is produced from Cosmo-SkyMed Stripmap
HIMAGE captured on May, 142015 with the spatial resolution is $2.5 \mathrm{~m}$. Terrain data is obtained by Digital Terrain Model (DTM) filter process to omit objects from bare earth. Height range is between $2 \mathrm{~m}$ and $113 \mathrm{~m}$ from the vertical datum which is mean sea level (MSL) of Tanjung Priok station.

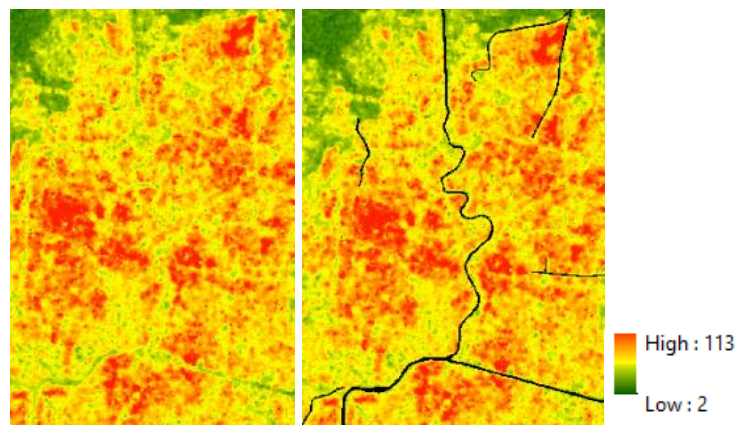

Figure 2. DTM data of Surabaya (b) Existing river overlaid with DTM

Based on this high precision of DTM data, object height can be recognized more precisely. Such that, lower area can be detected to classify the estimation of flood severity.

\section{METHODOLOGY}

\subsection{Flood Simulation Model}

Flood simulation model is generated from Landsat 8 imagery, terrain data, and rainfall monitoring data as the additional information. Distinguishing water surface into "temporary" and "permanent" water is the important process in the simulation model. Thus the "temporary" water is then assumed as flood over the study area. Indicating the "temporary" water si carried out by temporal analysis of Landsat data. Furthermore, the changes of water and building indices of temporal landsat date are used to indicate the existance of "temporary water".

3.1.1 Water Index: Modified Normalized Water Index (MNDWI) is the modification of Normalized Water Index. This algorithm is designed to optimalize the reflectance of green band to identify water and minimize the reflectance of Middle Infrared (MIR) to identify built-up land, vegetation, and soil reflect $(\mathrm{Xu}, 2019)$. The formula of MNDWI is expressed here;

$$
M N D W I=\frac{\text { Green }-M I R}{\text { Green }+M I R}
$$

Where green and MIR reflectance are band 3 and 6 of Landsat 8 respectively. By computing MNDWI, the extraction of water surface value enhances positive value close to 1 while build-up, vegetation, soil value decrease more negative or tend to be zero. MNDWI is the important parameter in detecting water surface changes among different Landsat data acquisition. Such that, "temporary" water surface can be identified.

3.1.2 Building Index: Normalized Difference Build-up Index (NDBI) is a build-up index designed to optimalize reflectance of MIR band to detect built-up land thus yields value close to 1 and minimize reflectance of NIR band to detect vegetation and wet surroundings (Rasul et al, 2018). The formula of NDBI is expressed here;

$$
N D B I=\frac{M I R-N I R}{M I R+N I R}
$$


Where MIR and NIR are band 6 and 5 of Landsat 8 respectively. By computing NDBI, built-up object can be distinguished from wet surroundings.

Classifying water index and building index are conducted in this research to detect potential inundation area of flood on March 2014. By assuming water surface area changes identification from NDWI extraction and built-up area from NDBI extraction, inundation area can be distinguished based on the significant contrast between wet and dry area extracted from both index. Besides recognizing the pattern of existing permanent water before flood event, the existing of built-up, soil and vegetation

\subsection{Network Analyst}

Network is carried out based on interconnected elements in a map such as edge, line, connecting junctions (point), that represent possible routes from one to another (ESRI, 2016). By modeling the travel path with a network, it can be easier to analyze the movement of vehicle behaviors such as performing the shortest path and fastest path upon evacuation route. The requirement of network analyst is network datasets or transportation networks which represent the street, pedestrian, or railroad, equipped with the directions.

This reserch produce network dataset based on Open street Map which contains street ID, street name, street class, surface condition, and oneway information. Network dataset is built up over the West of Surabaya street based on ground sampling data.

Ground sampling was conducted before building the network dataset in order to complement Open street map (OSM) metadata with direction, time travel, and measured distance. Parameters of determining the ground sampling object was street class and surface condition defined from OSM. The street class was divided into primary, secondary, tertiary, residential, living street, and trunk. While surface condition was divided into high damage, medium damage, and normal. Furthermore, travel time of each segment street was obtained by implementing this equations (1);

$$
S=v \times t
$$

where

$$
\begin{aligned}
& S=\text { distance } \\
& v=\text { average speed of vehicle } \\
& t=\text { travel time }
\end{aligned}
$$

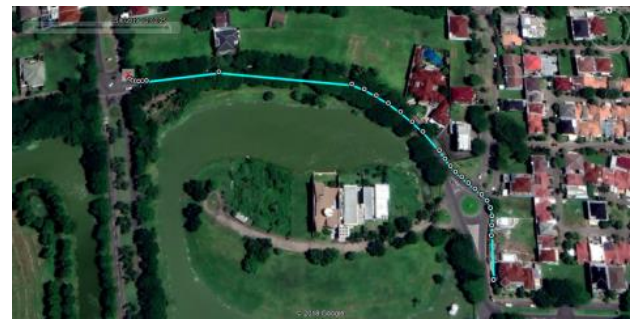

Figure 3. GPS tracking of Telaga Utama Street

$S$ and $t$ are measured using Global Positioning System (GPS) Garmin tracking. Figure 3 shows the example of GPS tracking record from Telaga Utama street (primary street) that yielded $S$ $=400 \mathrm{~m}, v=28,8 \mathrm{~km} /$ hour.

\section{RESULT AND DISCUSSION}

\subsection{Water Surface Detection}

Water surface detection is conducted by classifying MNDWI value into 4 classes composed of blue water, green water, shallow water, non water object. Based on supervised classification upon existing vector data from Geospatial Information Agency of Indonesia (BIG), permanent water surface is successfully generated with standard deviation 0.348 and overall accuracy $80 \%$.

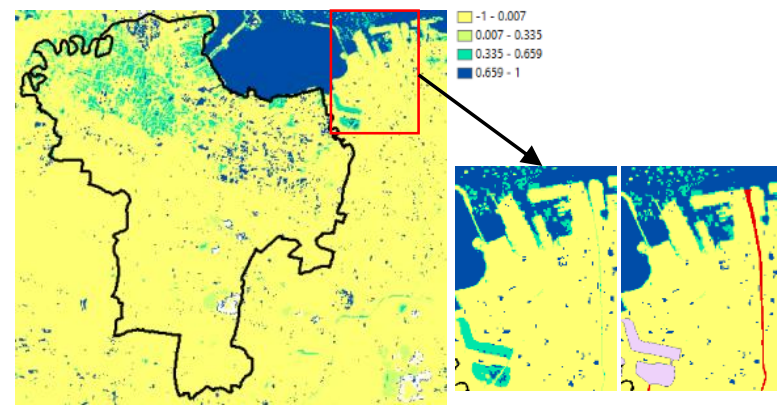

Figure 4. (a) Supervised classification of MNDWI before flood (b) MNDWI overlaid with existing river and lake from referenced vector

Figure 4 shows MNDWI computation of before flood event. The study area is depicted in black boundary. Assumming the permanent water is categorized as blue and green water e.g. sea, lake, pond, and reservoir, the temporary water can be further identified. Eventhough river is categorized as shallow water in this classification, the existance is relatively constant to be categorized into permanent. Such that, for indicating temporary water surface river can be ignored. The MNDWI classification value over the study area is described as follows;

Table 2. Supervised classification of MNDWI (Before Flood)

\begin{tabular}{|c|c|c|c|}
\hline Class & MNDWI & $\begin{array}{c}\text { Coverage } \\
\%\end{array}$ & $\begin{array}{c}\text { Area } \\
\left(\mathrm{km}^{2}\right)\end{array}$ \\
\hline $\begin{array}{c}\text { Blue water } \\
\text { Green water }\end{array}$ & $0.659-1$ & 3,64 & 4.177 \\
$\begin{array}{c}\text { Shallow, vegetation } \\
\text { water }\end{array}$ & $0.335-0.659$ & 6,13 & 7.026 \\
Non-water & $-1-0.007$ & 9,07 & 10.393 \\
& 81,15 & 92.972 \\
\hline
\end{tabular}

Ignoring the existance of clouds cover and null data in the water surface changes analysis, inundation area is generated based on water surface changes between before and after flood event. A number of increasing MNDWI value indicated on after flood event (see Table 3). It has larger contrast between water surface and non-water object than before flood event as shown in figure 5a. In addition, the dividing class of MNDWI becomes more generalized particularly water surface. The change of MNDWI class is affected by turbidity water of flood reflect more green band so that the value increase more positive (Mcfeeters, 2013; $\mathrm{Xu}, 2019)$. Thereby, potential inundation area can be identified precisely considering the existing permanent water indicated by MNDWI extraction before flood event. Figure $5 b$ depicts water surface changes detection with brown color as the result of MNDWI fusion between before and after flood event. 


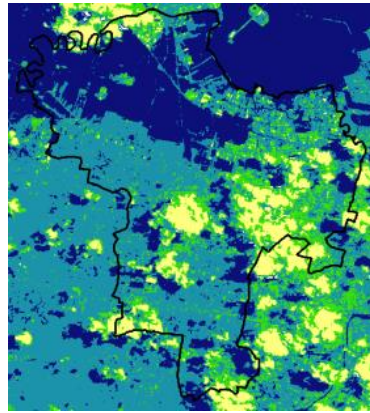

(a)

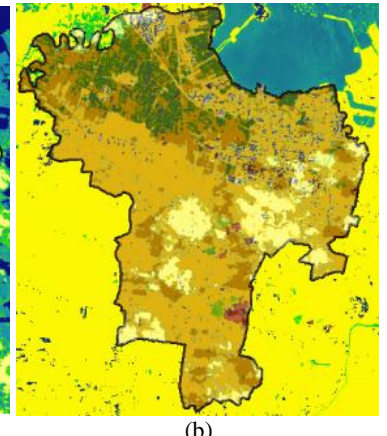

(b)
Figure 5. (a) NDWI Extraction after Flood Event (b) Water Surface Area Changes

Table 3. Supervised Classification of MNDWI (After Flood)

\begin{tabular}{|c|c|c|c|}
\hline Class & MNDWI & $\begin{array}{c}\text { Coverage } \\
\%\end{array}$ & $\begin{array}{c}\text { Area } \\
\left(\mathrm{km}^{2}\right)\end{array}$ \\
\hline Blue water & $0.659-1$ & 34,38 & 39,579 \\
Non water & $0.335-0.659$ & 46,32 & 53,333 \\
Cloud Shaddow & $0.007-0.335$ & 9,32 & 10,731 \\
Cloud cover & $-1-0.007$ & 9,97 & 11,483 \\
\hline
\end{tabular}

\subsection{Building detection}

Building detection is used to validate water surface changes as NDBI capable of distinguishing built-up and wet surroundings. So as to precisely validate the distribution of existing water surface, reclassifying the result of NDBI extraction before flood event is conducted to discriminate built-up, soil, and vegetation background from water surface. Supervised classification is carried out by dividing the class into turbid water, water, soil,vegetation and minor built-up, as well as major built-up with overall accuracy $80 \%$. Minor built-up described in this research as a number of building with soil and vegetation as the surroundings. Therefore minor building, soil, and vegetation are generelized at the same class in order to enhance water surface detection. The dividing class of NDBI before flood described in table 4.

Table 4. Supervised Classification of NDBI (Before Flood)

\begin{tabular}{|c|c|l|l|}
\hline Class & NDBI & \multicolumn{1}{|c|}{$\begin{array}{c}\text { Coverage } \\
\%\end{array}$} & $\begin{array}{c}\text { Area } \\
\left(\mathrm{km}^{2}\right)\end{array}$ \\
\hline Turbid Water & $-1--0.5$ & 4,56 & 4,007 \\
$\begin{array}{c}\text { Clean Water } \\
\text { Soil, Vegetation, }\end{array}$ & $-0.5--0.01$ & 16,4 & 14,403 \\
$\begin{array}{c}\text { Minor built- up } \\
\text { Major Built-up }\end{array}$ & $0.49-1$ & 2,38 & 79,493 \\
\hline
\end{tabular}

Based on the classification result depicted in figure 6, turbid water easier to be discriminated against other classes. Since turbid water reflects more NIR that cause the NDBI value has more negative. NDBI classification after flood event yields dividing class depicts cloud shaddow and cloud. Otherwise soi, vegetation and minor built-up area decrease significantly and turbid water increase accordingly. The capability of NDBI in discrimating built-up from wet surroundings has limitation in dry area (Rasul et al., 2018). Therefore minor built-up and soil difficult to identified in this study area where the study area is dominantly dry. Otherwise NDBI extraction after flood event detects more water (see Figure 7). It might caused by the soil condition after flood event triggers MIR reflects wet soil more than before flood event. Since NDBI poorly identify in semi arid area (Qian et al., 2007)

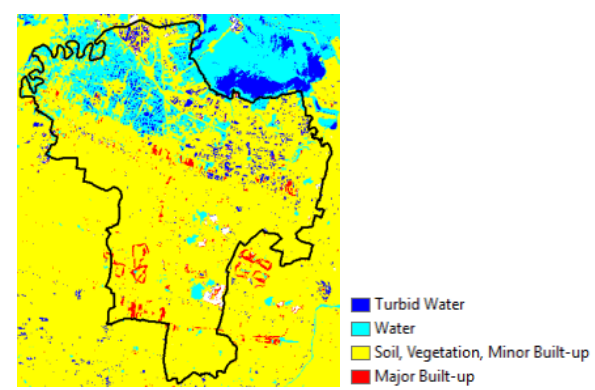

Figure 6. Classification of NDBI computation value

Table 5. Supervised Classification of NDBI (After Flood)

\begin{tabular}{|c|c|l|c|}
\hline Class & NDBI & $\begin{array}{c}\text { Coverage } \\
\%\end{array}$ & $\begin{array}{r}\text { Area } \\
\left(\mathrm{km}^{2}\right)\end{array}$ \\
\hline Turbid Water & $-1--0.5$ & 61,40 & 70,555 \\
Soil, Vegetation, & $-0.5--0.01$ & 32,18 & 36,975 \\
Built- up & & & \\
Clouds shaddow & $-0.01-0.49$ & 0,961 & 1,105 \\
Cloud cover & $0.49-1$ & 5,46 & 6,272 \\
\hline
\end{tabular}

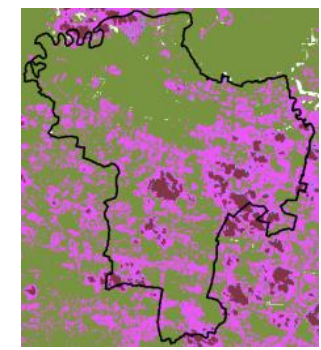

Figure 7. Classification of NDBI (After Flood)

\subsection{Flood Simulation Model}

Flood simulation model is generated by water surface detection using MNDWI and NDBI extraction. Before identifying inundation area, image fusion between MNDWI and NDBI is carried out to discriminate water surface from bare soil, vegetation and built-up object. Figure 8 shows the comparison between NDWI and NDBI. Both index succesfully discriminate water surface againts the surroundings. Eventhough NDBI extraction of water more rough, wet object can be discriminated againts dry object mainly building and soil.

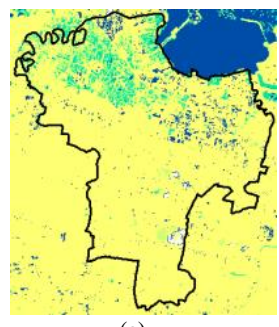

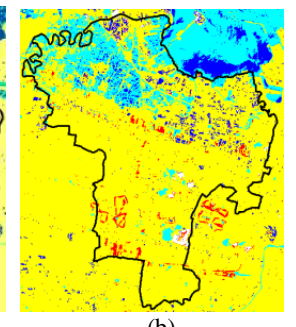

(b)
Figure 8 Comparison between (a) MNDWI and (b) NDBI in classifying water surface 

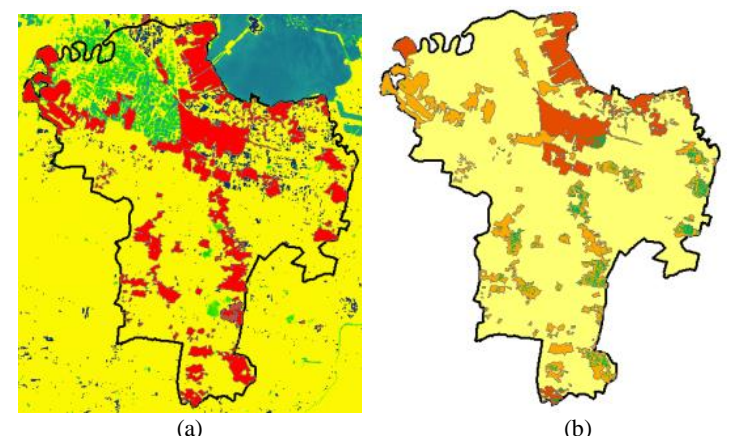

(b)
Figure 9. (a) Potential Inundation Area of Flood (b) flood severity

Flood severity is generated from image fusion betwen flood potential area with terrain data. This research assume the severity emphasize on the lowest area as the serious $(>0.5 \mathrm{~m})$ and sequentially. Serious categorized by $18-25 \mathrm{~m}$, moderate $(0,5-0,3 \mathrm{~m})$ categorized by $25-30 \mathrm{~m}$, and slight categorized by $30-35 \mathrm{~m}$, respectively in the reference terrain data. The severity class is depicted in figure $10 \mathrm{~b}$. Serious is depicted by brown, moderate and slight is described by orange color. Furthermore, impact analysis towards damage road and damage bridge is carried out. Based on the analysis, 698 road segments are submerged flood and 3 of 19 impacted bridge are within serious area (figure 11).

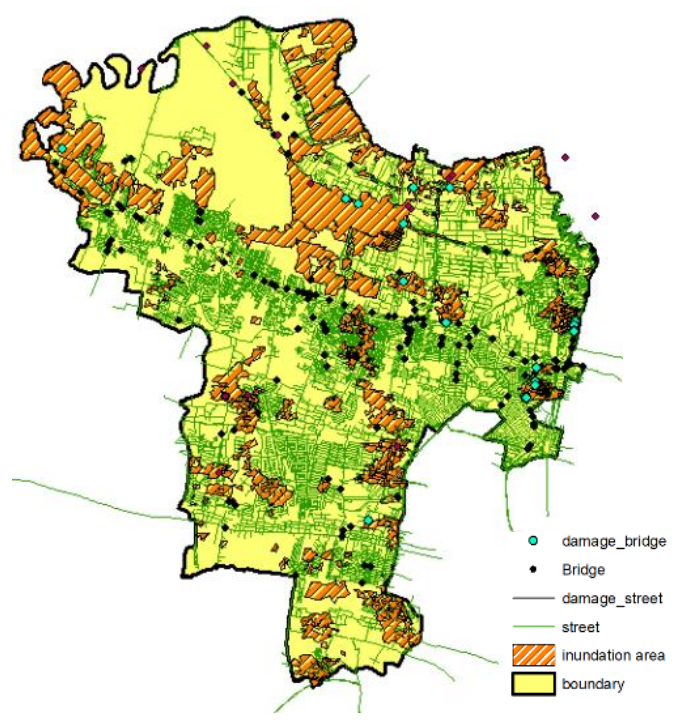

Figure 11. Facilily damage analysis

\subsection{Generating Evacuation Route}

An emergency decision may require to be made in the emergency situation when disaster strike to recover unplanned situation. For example changing street directions, damaged facilities, and moving vehicle stops (Bartolozzi et al., 2015). This research solve the tranportation issue in flood evacuation. By applying flood potential generated from previous analysis as barriers, this research simulate route analsys of Sememi Health Center surrounding area. Figure 13 depicts potential evacuation route around 30 minutes in accordance with time applied as the parameter of analysis before flood event. The destiation of evacuation is Sememi health center and the origin is the surrounding pedestrian. Sememi health center is chosen since the location is more accessible if flood occured compared with other health center. The location has minimum flood effect based on previous flood potential analysis.

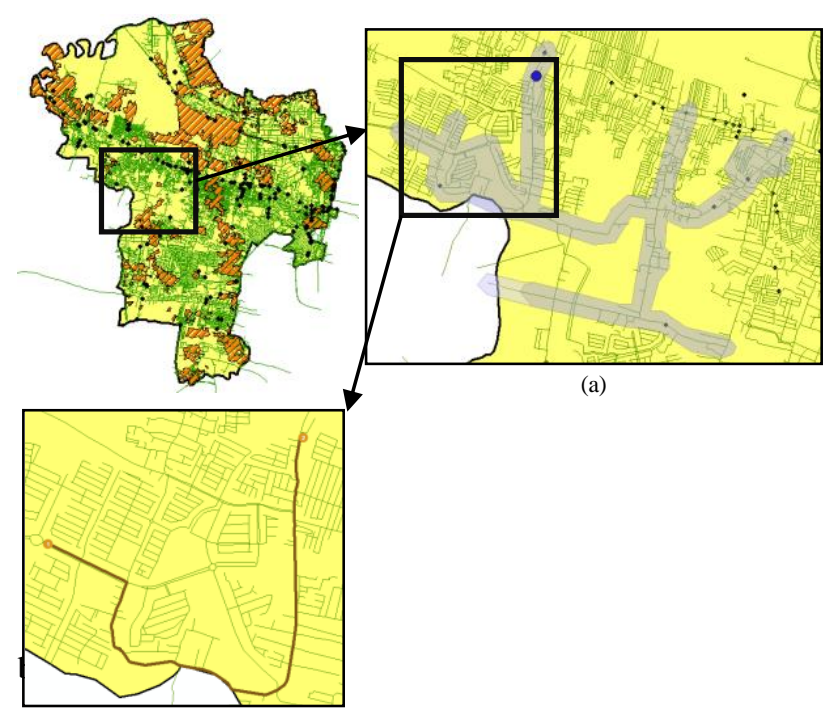

Figure 12. (a) The recommended route to Sememi health center from several origin (b) route to sememi health center from pedestrian

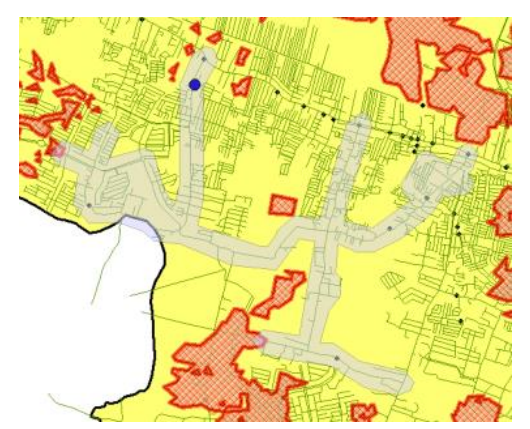

Figure 13. The recommended route after flood

Figure 13 depicts the recommended route decrease at the flood area. Eventhough the rest route still generates the same covered area. Such that, this recommended route can be the alternative route for evacuation procedure of Sememi health center surroundings. The route all contains residential street $<2 \mathrm{~m}$ width and no described name. The average speed of this alternative route is $20 \mathrm{~km} / \mathrm{hr}$.

\section{CONCLUSION}

Flood potential map is successfully generated from image fusion between before and after flood utilizing MNDWI and NDBI classification. The result shows MNDWI has more accurate value than NDBI in discriminating water surface. Flood severity is classified based on image fusion between terrain and flood potential, the severity is dominated by slight and moderate. From flood potential analysis, evacuation route analysis is carried out at Sememi Health Center surrounding area based on 30 minutes coverage area. The recommended route reveals the effectiveness as the generating route after flood event remain the same. This paper is ongoing reseacrh in which the flood potential will be developed considering water level in order to enhance the classification of flood depth. 


\section{ACKNOWLEDGEMENTS (OPTIONAL)}

Thank you for Reseacrh an Service Institution of Institut Teknologi Sepuluh Nopember Surabaya (LPPM ITS) for reseacrh funding.

\section{REFERENCES}

A. Ertug Gunes and Jacob P. Kovel, P.E., Member, A. (2001). USING GIS IN EMERGENCY MANAGEMENT OPERATIONS By, 126(3), 136-149.

Bartolozzi, M., Bellini, P., Nesi, P., Pantaleo, G., \& Santi, L. (2015). A smart decision support system for smart city. Proceedings - 2015 IEEE International Conference on Smart City, SmartCity 2015, Held Jointly with 8th IEEE International Conference on Social Computing and Networking, SocialCom 2015, 5th IEEE International Conference on Sustainable Computing and Communic, 117-122. https://doi.org/10.1109/SmartCity.2015.57

BMKG. (2019). Prakiraan Musim Kemarau 2019 di Indonesia. BMKG. Retrieved from bmkg.go.id

Dao, P. D., Liou, Y., \& Chou, C. (2015). Detection of Flood Inundation Regions with Landsat / MODIS Synthetic Data DETECTION OF FLOOD INUNDATION REGIONS WITH LANDSAT / MODIS SYNTHETIC DATA, (April).

ESRI. (2006). GIS and Emergency Management in Indian Ocean Earthquake / Tsunami Disaster. New York, (May), 40. Retrieved from http://www.esri.com/library/whitepapers/pdfs/gis-andemergency-mgmt.pdf

Esri, A., \& Paper, W. (2000). Challenges for GIS in Emergency Preparedness and Response. Challenges for GIS in Emergency Preparedness and Response, (May), 29.

Huder, R. C. (2012). Disaster Operations and Decision Making. A JOHN WILEY \& SONS, INC., PUBLICATION.

Mansourian, A., Rajabifard, A., Valadan Zoej, M. J., \& Williamson, I. (2006). Using SDI and web-based system to facilitate disaster management. Computers and Geosciences, 32(3), 303-315. https://doi.org/10.1016/j.cageo.2005.06.017

Mcfeeters, S. K. (2013). Using the Normalized Difference Water Index (NDWI) within a Geographic Information System to Detect Swimming Pools for Mosquito Abatement: A Practical Approach, 3544-3561. https://doi.org/10.3390/rs5073544

Nicoara, P.-S., \& Haidu, I. (2014). a Gis Based Network Analysis for the Identification of Shortest Route Access To Emergency Medical Facilities. Geographica Technica, 09(2), 60-67.

Pasha, I. (2006). Ambulance management system using GIS. Ambulance Management, 1-78.

Rasul, A., Balzter, H., Faqe, G. R., Id, I., \& Hameed, H. M. (n.d.). Applying Built-Up and Bare-Soil Indices from. https://doi.org/10.3390/land7030081

United Nations. (2008). Disaster Preparedness for Effective Response. Framework.

Westen, C. Van. (2012). Remote Sensing and GIS for Natural Hazards Assessment and Disaster Risk Management. ... of Space Technology for Disaster Risk Reduction: ..., 161. https://doi.org/http://dx.doi.org/10.1016/B978-0-12374739-6.00051-8

Xu, H. (2019). Modification of Normalized Difference Water Index ( NDWI ) to Enhance Open Water Features in Remotely Sensed Imagery, (July 2006). https://doi.org/10.1080/01431160600589179
Zhacky, M. 2019. Banjir-Longsor Banyak Telan Korban Jiwa, BNPB Minta Masyarakat Waspada. Source: https://news.detik.com/berita/d-4410459/banjir-longsorbanyaktelan-korban-jiwa-bnpb-minta-masyarakatwaspada. Accessed on Feb 20, 2019 